\title{
Promoter-Dependent Activity on Androgen Receptor N-Terminal Domain Mutations in Androgen Insensitivity Syndrome
}

\author{
Rieko Tadokoro-Cuccaro ${ }^{a} \quad$ John Davies ${ }^{a} \quad$ Nigel P. Mongan $^{b}$ Trevor Bunch $^{a}$ \\ Rosalind S. Brown ${ }^{c}$ Laura Audi ${ }^{d}$ Kate Watt ${ }^{\mathrm{e}}$ lain J. McEwan ${ }^{\mathrm{e}}$ \\ leuan A. Hughes ${ }^{a}$

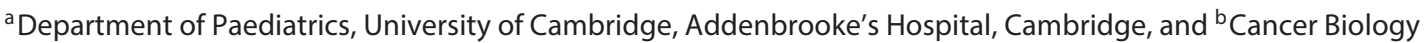 \\ and Translational Research, Faculty of Medicine and Health Sciences, School of Veterinary Medicine and Science, \\ University of Nottingham, Nottingham, UK; ' $D$ ivision of Endocrinology, Boston Children's Hospital, Boston, Mass., \\ USA; ${ }^{d}$ Paediatric Endocrinology Research Unit, Vall d'Hebron Research Institute (VHIR), Center for Biomedical \\ Research Network on Rare Diseases (CIBERER), Autonomous University of Barcelona (UAB), Barcelona, Spain; \\ e Department of Molecular and Cell Biology, Institute of Medical Sciences, University of Aberdeen, Aberdeen, UK
}

\section{Key Words}

Androgen insensitivity syndrome $\cdot$ Androgen receptor .

$\mathrm{N}$-terminal domain

\begin{abstract}
Androgen receptor (AR) mutations are associated with androgen insensitivity syndrome (AIS). Missense mutations identified in the AR-N-terminal domain (AR-NTD) are rare, and clinical phenotypes are typically mild. We investigated 7 missense mutations and 2 insertion/deletions located in the AR-NTD. This study aimed to elucidate the pathogenic role of AR-NTD mutants in AIS and to use this knowledge to further define AR-NTD function. AR-NTD mutations (Q120E, A159T, G216R, N235K, G248V, L272F, and P380R) were introduced into AR-expression plasmids. Stably expressing cell lines were established for del57L and ins58L. Transactivation was measured using luciferase reporter constructs under the control of GRE and Pem promoters. Intrinsic fluorescence spectroscopy and partial proteolysis studies were performed for mutations which showed reduced activities by using a
\end{abstract}

purified AR-AF1 protein. Pem-luciferase reporter activation was reduced for A159T, N235K, and G248V but not the GREluciferase reporter. Protein structure analysis detected no significant change in the AR-AF1 region for these mutations. Reduced cellular expression and transactivation activity were observed for ins58L. The mutations Q120E, G216R, L272F, P380R, and del57L showed small or no detectable changes in function. Thus, clinical and experimental analyses have identified novel AR-signalling defects associated with mutations in the structurally disordered AR-NTD domain in patients with AIS.

(C) 2014 S. Karger AG, Basel

Androgen insensitivity syndrome (AIS) is a major cause of 46,XY disorders of sexual development. Affected individuals usually present with primary amenorrhea in adolescence or with inguinal swellings containing testes in infancy [Hughes et al., 2012], which is characteristic for a complete resistance to androgens. However, there is a broad spectrum of undervirilised external genitalia, de-

\section{KARGER}

E-Mail karger@karger.com

www.karger.com/sxd (c) 2014 S. Karger AG, Base

1661-5425/14/0086-0339\$39.50/0
Rieko Tadokoro-Cuccaro

Department of Paediatrics, University of Cambridge

Addenbrooke's Hospital, Hills Road

Cambridge, CB2 0QQ (UK)

E-Mail riekotmm@ @otmail.co.uk 
pending on the ability to respond to androgens. AIS is sub-classified into 3 clinical categories: complete (CAIS), partial (PAIS), and mild type (MAIS). A mutation of the androgen receptor $(A R)$ gene, located on the $\mathrm{X}$ chromosome (Xq11.2q12), is the only established molecular cause of AIS.

$\mathrm{AR}$ is a member of the steroid nuclear receptor subfamily of ligand-dependent transcriptional factors. It comprises an N-terminal domain (AR-NTD), a central DNA-binding domain (AR-DBD), and a ligand-binding domain (AR-LBD). AR interacts with a wide range of coregulator proteins, including epigenetic co-activators and components of the general transcription machinery. In the presence of an agonist, AR initiates a sequence of chromatin remodelling and histone modifications which promote transcriptional activation [Heemers and Tindall, 2007]. The AR-NTD is the least conserved domain as compared to other members of the steroid receptor family [McEwan, 2004]. It contains the ligand-independent activation function-1 (AF1). Two smaller transactivation units are also defined which are responsible for more than 50\% AR-NTD activity: Tau-1 (amino acids 101-370) and Tau-5 (amino acids 360-528) [Jenster et al., 1995]. The AR-NTD has a disordered flexible structure and has so far resisted resolution by X-ray crystallography [Zhou et al., 2010]. Features unique to the AR-NTD are the glutamine (normal range 8-31) and glycine repeats (normal range 10-27) [Jääskeläinen, 2012]. As determined in vitro, variation of repeat length within the respective normal ranges affects AR transactivation activity [Kazemi-Esfarjani et al., 1995].

The most frequent pathogenic $A R$ gene defects are missense mutations, a large majority of which have been identified in the AR-LBD and AR-DBD (http://androgendb.mcgill.ca/) [Gottlieb et al., 2012]. The missense mutations identified to date in the AR-NTD are generally associated with milder clinical phenotypes [Gottlieb et al., 1999]. A possible explanation for this observation relates to the structural flexibility of the AR-NTD which may enable the AR to tolerate amino acid substitutions with little functional consequence. Pathogenic missense mutations within the AR-NTD would therefore provide a valuable tool to better define the structure-function relationship of this domain. Consequently, we have investigated 7 missense mutations and 2 insertion/deletion slippage mutations identified in our large database of patients with AIS who have proven $A R$ mutations. This study aimed to define the pathogenicity for these ARNTD mutants and to further understand the molecular function of the AR-NTD.

\section{Patients and Methods}

\section{Subjects}

All studies were conducted in accordance with approval of the local research ethics committee, and informed consent was obtained to use patient samples for diagnosis and the Disorders of Sex Development research program. Mutations Q120E, G216R, G248V, L272F, del57L (Q57L), and ins58L (Q58L) (table 1) were from the Cambridge DSD database. A159T, N235K, and P380R were also reported previously [Giwercman et al., 2001; Mueller et al., 2006; Audi et al., 2010].

\section{Plasmid Constructs}

An $A R$ cDNA construct pSVAR0 [Brinkmann et al., 1989] and 2 luciferase reporter constructs, pGRE2-TATA-Luc [Knoke et al., 1999] and pPEM-Luc [Barbulescu et al., 2001], have previously been described. Renilla luciferase construct pRL-TK (Promega) was used as a control. Missense mutations and del57L were introduced into pSVAR0 using a QuikChange XL site-directed mutagenesis kit (Stratagene). Ins58L was generated by routine PCR, and the $A R$-fragment was cloned into pSVAR0 via pGEM-T Easy (Promega). The $A R$ cDNA was fully sequenced for verification.

\section{Transactivation Assays}

A volume of $1.25 \times 10^{5} /$ well COS- 1 cells (American Type Culture Collection) were seeded into 12 -well tissue culture plates in Dulbecco's modified essential medium (DMEM) containing $2 \mathrm{mM}$ glutamine and $10 \%$ charcoal-stripped serum. After $24 \mathrm{~h}$, cells were transiently transfected with $25 \mathrm{ng}$ pSVAR0 or the vector encoding the mutation, $500 \mathrm{ng}$ either pGRE2-TATA-Luc or pPEM-Luc, and $25 \mathrm{ng}$ pRL-TK. Lipofectin transfection reagent (Invitrogen) was used with Opti-MEM (Invitrogen) according to the manufacturer's instructions. A volume of $0-10 \mathrm{nmol} / \mathrm{l}$ dihydrotestosterone (DHT; Sigma) was added to the cells $16 \mathrm{~h}$ after transfection. Twenty-four hours after the addition of the hormone, the cells were harvested in $500 \mu \mathrm{l}$ lysis buffer ( $25 \mathrm{mM}$ glycylglycine $\mathrm{pH}$ 7.8, $15 \mathrm{mM} \mathrm{MgSO}_{4}, 4$ mM EGTA, 1 mM dithiothreitol, and $1 \%$ Triton X), and the ratio of firefly to Renilla luciferase was measured with reagents from Nanolight technology using a Centro/Centro XS3 Microplate Luminometer LB 960 (Berthold Technologies). For Flp-In 293 cell transfection (Invistrogen), $2 \times$ $10^{5}$ cells/well were seeded and were transfected after $48 \mathrm{~h}$ with 500 ng pGRE2-TATA-Luc and $25 \mathrm{ng}$ pRL-TK, using Lipofectin with Opti-MEM. Harvest and transactivation assay procedures were the same as previously described.

\section{Western Blot}

A total of $20 \mu \mathrm{g}$ of whole cell extract was analysed by SDSPAGE and transferred to an Immobilon-P membrane (Millipore). The blot was probed with primary rabbit anti-AR antibody (Sc816 , Santa Cruz), followed by anti-rabbit horseradish peroxidaseconjugated secondary antibodies (Dako) and visualised with ECL Blotting Detection reagent (GE Healthcare). After Western blotting, the membranes were stained with $0.5 \%$ Ponceau $\mathrm{S}$ in $1 \%$ acetic acid to confirm equal protein transfer.

Generation of Mutant AR Stably Expressed in HEK293 Cell Lines

Wild-type and mutant $A R$ (ins58L, del57L) were subcloned into the recombination vector pcDNA5/FRT using KpnI and NheI 
Table 1. List of the 9 AR-NTD mutations analysed, reported phenotypes, and functional studies published previously

\begin{tabular}{|c|c|c|c|c|c|}
\hline Q120E & PAIS & $\mathrm{F}$ & $\begin{array}{l}\text { clitoromegaly, uterus and fallopian tube } \\
\text { present }\end{array}$ & $\begin{array}{l}\text { mother is a carrier, } \\
\text { maternal grandfather } \\
\text { has the same } \\
\text { mutation }\end{array}$ & \\
\hline A159T & AIS & unknown & unknown & & Mueller et al. [2006] \\
\hline G248V & MAIS & M & hypospadias, decreased body hair & $\begin{array}{l}\text { sibling has similar } \\
\text { symptoms }\end{array}$ & Mueller et al. [2006] \\
\hline L272F & PAIS/MAIS & $\mathrm{F}$ & $\begin{array}{l}\text { micropenis, both gonads in right inguinal } \\
\text { region }\end{array}$ & & Ferlin et al. [2006] \\
\hline P380R & PAIS & M & $\begin{array}{l}\text { micropenis, scrotal hypospadias, bifid } \\
\text { scrotum, small for gestational age, uterus } \\
\text { and fallopian tube present }\end{array}$ & & Audi et al. [2010] \\
\hline $\begin{array}{l}\text { Del57L } \\
\text { (L57Q) }\end{array}$ & PAIS/MAIS & $\begin{array}{l}\text { Pt1: } M \\
\text { Pt2: M }\end{array}$ & $\begin{array}{l}\text { micropenis, undescended testis } \\
\text { micropenis }\end{array}$ & $\begin{array}{l}\text { mother of } \mathrm{Pt} 1 \text { is a } \\
\text { carrier }\end{array}$ & Tilley et al. [1996] \\
\hline
\end{tabular}

$\mathrm{Pt}=$ Patient; $\mathrm{TA}=$ transactivation compared to wild type.

sites. Flp-In 293 cells were cultured in DMEM, 10\% FBS, glutamine, Pen-Strep, and $100 \mu \mathrm{g} / \mathrm{ml}$ Zeocin. A volume of $2 \times 10^{6}$ cells were plated in 60 - $\mathrm{mm}$ tissue culture dishes $48 \mathrm{~h}$ prior to transfection. Cells were transfected with $4 \mathrm{ml}$ of Opti-MEM containing 0.8 $\mu \mathrm{g}$ pcDNA5/FRT-AR exchange plasmid, $7.2 \mu \mathrm{g}$ Flp recombinase expression plasmid pOG44, and $20 \mu$ Lipofectamine 2000. After $48 \mathrm{~h}$, the cells were split into dishes and cultured in DMEM, 10\% FBS, glutamine, Pen-Strep, and $200 \mu \mathrm{M}$ HygromycinB (Invitrogen). Individual colonies were transferred on day 10 . Zeocin sensitivity at $100 \mu \mathrm{g} / \mathrm{ml}$ was tested in each cell line to verify FRT-sitespecific integration of the receptor.

\section{Protein Expression and Purification}

Bacterial expression vectors pET-AR4 and pGEX-AR4 containing the human AF1 domain of the AR (amino acids 142-485) were used [Reid et al., 2002a]. Mutations A159T, N235K, and G248V were introduced into the vectors using a QuikChange site- directed mutagenesis kit and verified by direct sequencing. ARAF1 proteins were purified as described previously [Lavery and McEwan, 2008]. Proteins were assessed for purity by SDS-PAGE and scanning of stained gels using Image J (NIH).

\section{Intrinsic Fluorescence Emission Spectroscopy}

Fluorescence measurements were made using a Shimadzu 1501 spectrofluorimeter with excitation and emission band width of 10 $\mathrm{nm}$ using a $1-\mathrm{cm}$ path-length cuvette. The fluorescence spectra of AR-AF1 mutants were generated at excitation wavelengths of 278 and $295 \mathrm{~nm}$ and emission wavelengths read between 300 and 450 $\mathrm{nm}$. Folded and unfolded profiles of the proteins were also measured using trimethylamine N-oxide (TMAO; Sigma) and urea (Sigma). Histidine tagged proteins $(25 \mu \mathrm{g})$ were prepared both in $200 \mu \mathrm{l} \mathrm{di-}$ alysis buffer [Lavery and McEwan, 2008] and another dialysis buffer with $2 \mathrm{M}$ TMAO or $3 \mathrm{M}$ urea. Samples were measured in duplicate. All spectra were corrected for contributions of the buffer and solutes. 
Fig. 1. DHT-dependent transactivation assay for wild type and mutants Q120E, A159T, G216R, N235K, G248V, L272F, and P380R. COS-1 cells were transiently transfected with pSVAR0 or the plasmid containing the mutation, TAT-GRE promoter (A) or Pem promoter (B), and pRL-TK. Twenty-four hours after the addition of DHT, the cells were harvested and luciferase assays were performed at a minimum of 3 independent experiments. Standard error bars are shown. ${ }^{*}$ and ${ }^{* *}$ indicate $p \leq 0.05$ and $p \leq 0.01$, respectively, against the wild type. C Western blot of whole cell lysates of COS-1 cells transiently transfected with the plasmid encoding the wild-type or mutant receptor showing AR expression in the absence (-) or presence (+) of $10 \mathrm{nM}$ DHT.

\section{GRE-luciferase}

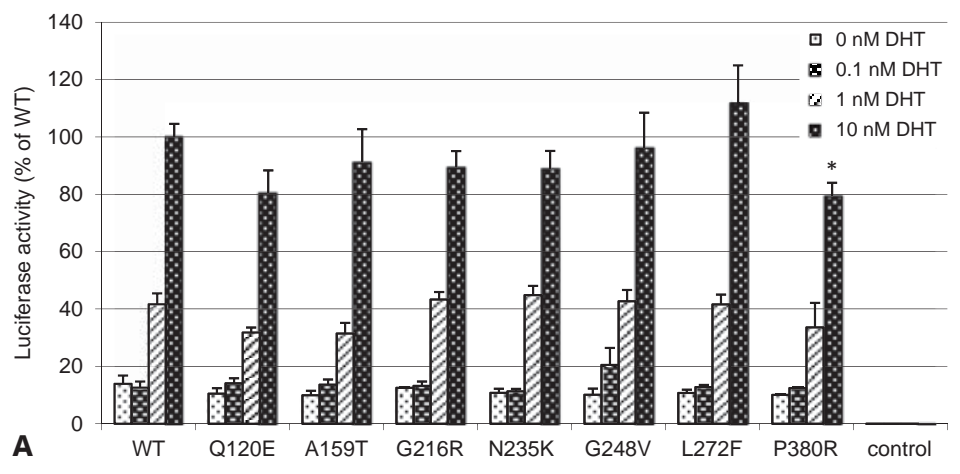

Pem-luciferase
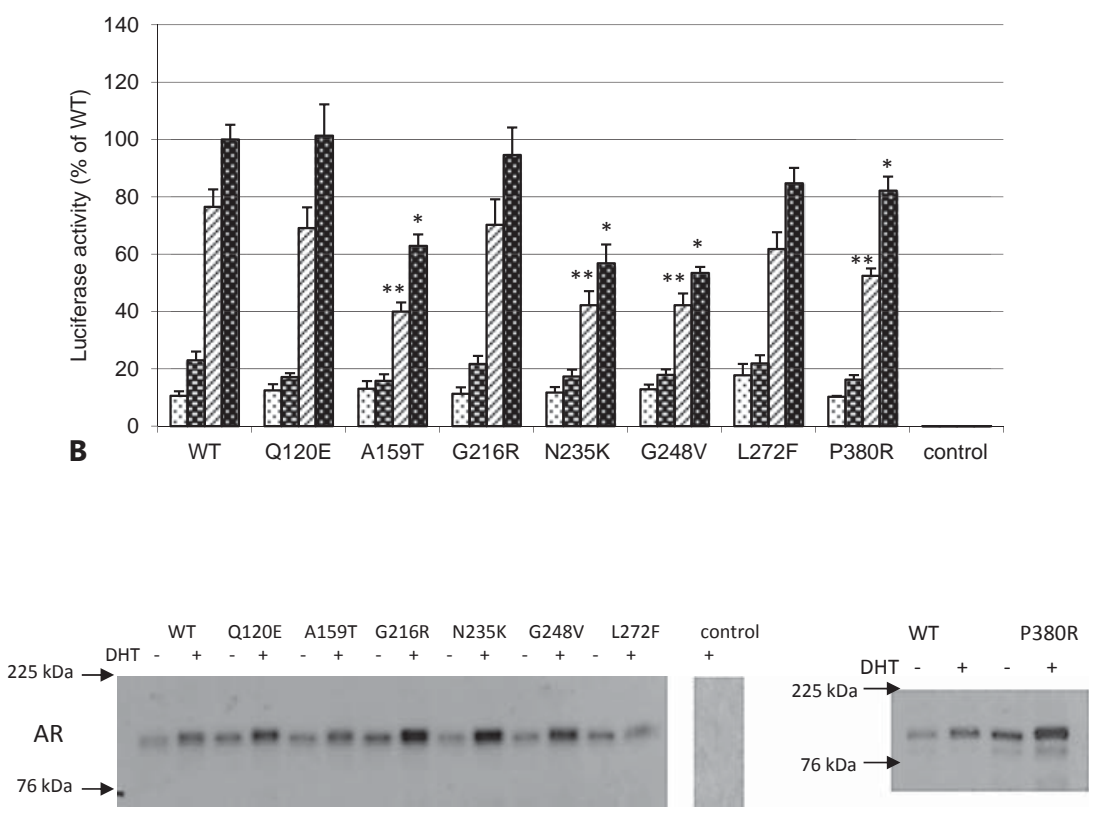

C

\section{Partial Proteolysis Analysis}

Histidine and GST-tagged AF1 proteins $(50 \mathrm{pmol})$ were diluted in proteolysis buffer [Lavery and McEwan, 2008] or proteolysis buffer with $2 \mathrm{M}$ TMAO. The proteins were treated with $6 \mathrm{ng}$ trypsin (Roche), 6 ng chymotrypsin (Roche), and 50 ng endoproteinase GluC (New England Biolabs) over a series of time points at room temperature. Reactions were stopped by addition of $5 \times$ SDS-PAGE sample buffer. Samples were heated at $75^{\circ} \mathrm{C}$ for $5 \mathrm{~min}$, were resolved by SDS-PAGE on a $12.5 \%$ gel, and fragments were analysed by Coomassie staining. For analysis, gels were dried on 3MM filter paper and scanned. Protein bands on the digitised image were analysed using the Image J program.
Statistical Analysis

A t test was used to assess differences between groups as indicated in the text. Differences were considered significant at $\mathrm{p} \leq 0.05$.

\section{Results}

\section{Transactivation Activity of AR-NTD Mutants}

Transcriptional activity of the missense mutations was examined using the GRE (fig. 1A) and the Pem promoter 


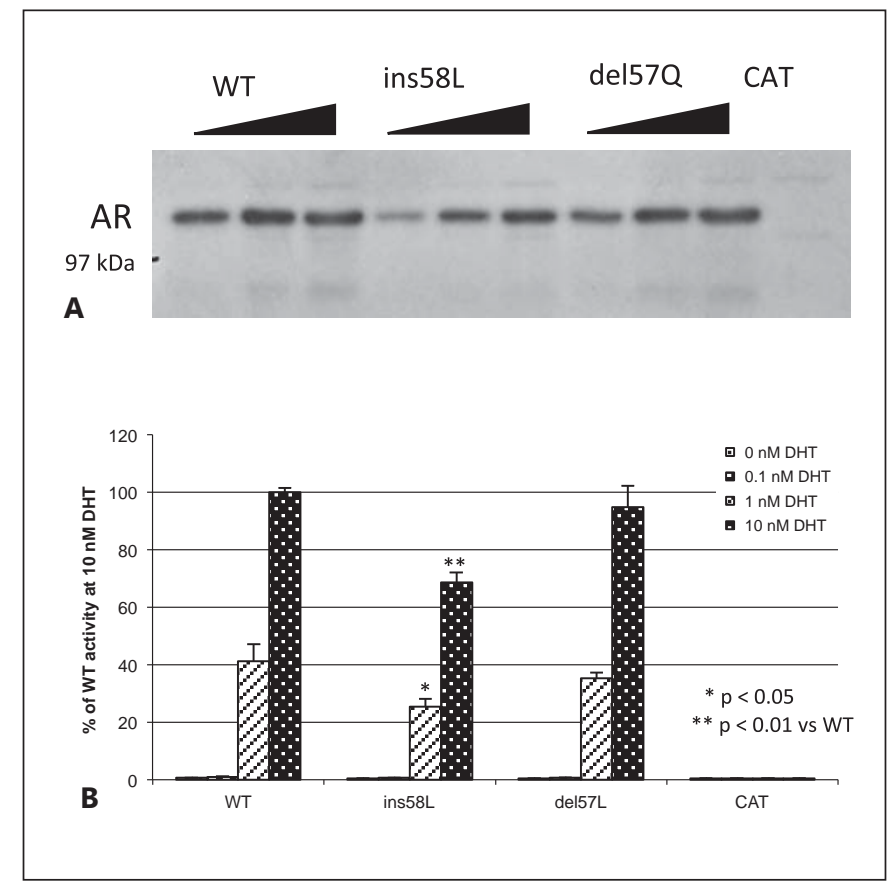

Fig. 2. Receptor protein levels and GRE reporter transactivation in HEK293 cells stably expressing wild-type AR, ins58L (Q58L) or del57L (L57Q). A Western blot of stable cell lines expressing WT AR, ins58L, del57L, or control (CAT). The amount of whole cell lysate loaded was $2.5,5$, and $10 \mu \mathrm{g} /$ lane. CAT: $10 \mu \mathrm{g}$. B TAT-GRE2 reporter transactivation in cells stably expressing WT AR, ins58L, del57L, or the negative control expressing CAT.

(fig. 1B). Western blotting verified similar cellular levels for mutant and wild-type receptor (fig. 1C). GRE promoter activity was reduced about $20 \%$ for Q120E relative to wild-type levels at $1 \mathrm{nM}$ and $10 \mathrm{nM} \mathrm{DHT}$, respectively. Q120E showed normal activity when measured under the Pem promoter. A159T, N235K, and G248V exhibited a statistically significant loss-of-function phenotype, responding with only $\sim 60 \%$ of wild-type AR activity in the $P e m$-luciferase reporter in response to DHT (10 nM). Interestingly, for these 3 mutations, no significant difference in the transactivation function in response to DHT as compared to wild-type AR was detected using the GRE-luciferase reporter. Similarly, the L272F mutation showed a non-significant reduction $(\sim 15 \%, \mathrm{p}=0.371)$ in DHT responsiveness under the Pem-luciferase reporter as compared to wild-type AR, but no functional deficit was detected for L272F using the GRE-luciferase reporter. In contrast, the P380R mutation reduced DHT-induced transactivation significantly $(\sim 20 \%)$ relative to the wild type for the GRE-luciferase reporter (DHT, $10 \mathrm{nM}$ ) and the Pem-luciferase at both 1 and $10 \mathrm{~nm} \mathrm{DHT}$.

Androgen Receptor N-Terminal Domain Mutations and Function

\section{Function and Expression of Slippage Mutations}

The mutations del57L and ins58L are located in a stretch of 4 leucines immediately $\mathrm{N}$-terminal of the AR polyglutamine repeat. The $A R$ mRNA sequence encoding these 4 leucines ( $5^{\prime}$-UUGCUGCUGCUG-3') complements the $A R$ mRNA sequence encoding the polyglutamine repeat $\left(5^{\prime}\right.$-CAGCAGCAGCAA- $\left.3^{\prime}\right)$, and both are believed to form a stable RNA stem structure [Yeap et al., 2004]. We hypothesised that insertion of an additional leucine codon may stabilise this AR stem-loop structure with the pathologic effect of hindering ribosome movement, translational accuracy or transcriptional/translational efficiency, resulting in a decreased AR protein synthesis. Conversely, this model would predict that deletion of a leucine codon would shorten the stem, potentially reducing its stability, but would not negatively impact on AR synthesis. To test functionality, we introduced the mutations ins58L and del57L into pSVAR0, and HEK293 cell lines stably expressing these mutants or wild-type AR were generated. Western blotting showed a lower protein level for ins58L relative to the wild type (fig. 2A). Multiple $(\mathrm{n}=5)$ independent expressing clones were tested, and the results were reproducible. Consistent with our model, expression of del57L was similar to the wild-type protein. Transactivation activity of ins58L was $70 \%$ of the wild-type $(\mathrm{p}<0.05)$ with DHT at 1 and $10 \mathrm{nM}$. del57L had an almost identical activity as the wildtype protein (fig. 2B). The results indicate that ins $58 \mathrm{~L}$ has a reduced transactivation activity relative to the wild type and to del57L.

\section{Protein Structure Analysis Using Intrinsic \\ Fluorescence Emission Spectroscopy}

Intrinsic fluorescence emission spectroscopy was used to further evaluate the effects of mutations on the structure of the AR-NTD. Recombinant protein fragments of the wild-type AR-AF1 subdomain of the ARNTD and AR-AF1 containing the A159T, N235K, and G248V mutations were purified. Wild-type AR-AF1 is composed of $22-26 \% \alpha$-helices, $5-12 \% \beta$-strands, and $64-69 \%$ random coils, and 3 helical regions were predicted [Reid et al., 2002a; Kumar et al., 2004]. Structure prediction analysis for A159T suggested a partial disruption of the first $\beta$-strand. $\mathrm{N} 235 \mathrm{~K}$ is located in the second $\alpha$-helix and is predicted to have no effect on the helical structure but may disrupt the following $\beta$-strand. G248V is located between the second and third $\alpha$-helix and may impact on the local structure. Intrinsic fluorescence emission spectroscopy was performed on proteins in their native state, a folded state induced by 
TMAO, and an unfolded state induced by urea. TMAO has been found to promote a natural folded structure for polypeptides that have a disordered structure [Kumar et al., 2004]. Intrinsic fluorescence emission spectra for tyrosine and tryptophan residues were measured using an

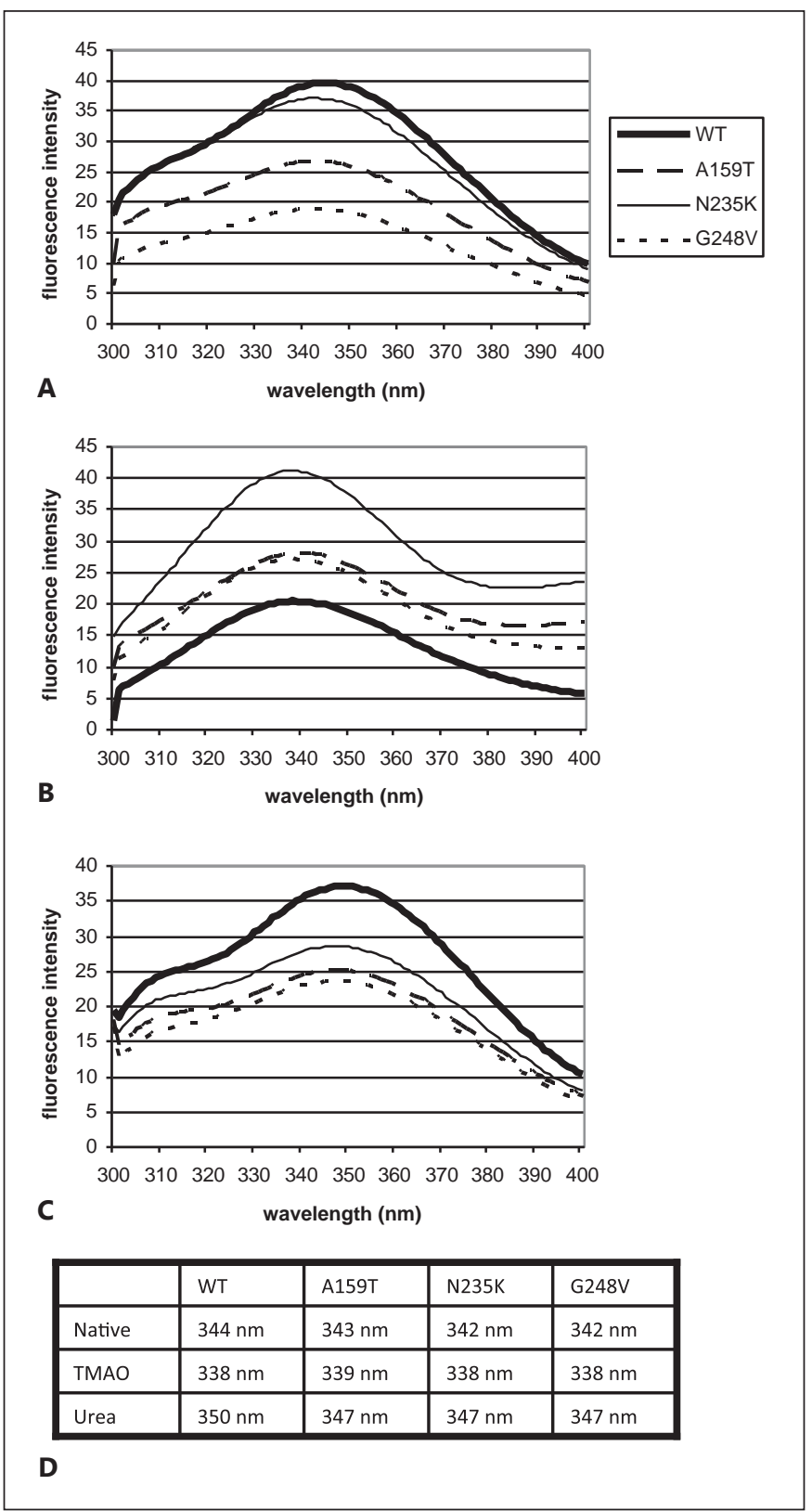

Fig. 3. Steady-state fluorescence emission spectra of wild-type and mutant AF1 domains (A159T, N235K, and G248V) in A dialysis buffer after excitation at $278 \mathrm{~nm}$, B $2 \mathrm{M} \mathrm{TMAO}$, and C $3 \mathrm{M}$ urea. Intrinsic fluorescence of tyrosine and tryptophan residues was measured using an excitation wavelength of $278 \mathrm{~nm}$. D Summary of the emission maximum ( $\lambda \max$ ) of wild-type and mutant AF1 domains in native, folded, and unfolded states. excitation wavelength of $278 \mathrm{~nm}$ (fig. 3). The excitation wavelength $295 \mathrm{~nm}$ measured only the steady-state emission for tryptophan. AR-AF1 contains 13 tyrosine residues and 2 tryptophan residues. The spectrum provides information on the local conformation surrounding these residues. At an excitation of $278 \mathrm{~nm}$, the wildtype AR-AF1 and the mutants showed the same emission maximum at $343 \mathrm{~nm}$ due to the tryptophan residues and a shoulder at $309 \mathrm{~nm}$ due to tyrosine emission. In the presence of TMAO, the tryptophan emission maximum $(\lambda \max )$ blue-shifted to $338 \mathrm{~nm}$, and the shoulder due to tyrosine emission was lost for all the proteins. This indicates that the tryptophan residues become less exposed to the solvent in the presence of TMAO, consistent with AR-AF1 developing a more structured conformation. Treatment with urea caused the opposite effect on all 4 proteins, the peak spectra red-shifted to $347 \mathrm{~nm}$, resulting from the tryptophan residues becoming more solvent-exposed. The measurement at an excitation of $295 \mathrm{~nm}$ showed a similar trend (data not shown).

\section{Partial Proteolysis}

The local structure of wild-type AR-AF1 protein and the mutants were analysed by partial proteolysis, using the enzymes trypsin, chymotrypsin, and endoproteinase GluC (Endo-GluC). Cleavage of AR-AF1 was investigated in the presence or absence of TMAO. Figure $4 \mathrm{~B}$ shows an example of the Endo-GluC digestion. Endo-GluC cleaves at 23 sites, some of which are closer to the mutated amino acid residues compared to trypsin or chymotrypsin cleavage sites (fig. 4A). The digestion rates of all proteins were reduced in the presence of TMAO compared to experiments lacking TMAO. This is consistent with stabilisation and the adoption of a more folded composition of AR-AF1 in the presence of TMAO. However, no qualitative or quantitative difference was observed between the wild-type and mutant proteins in the presence or absence of TMAO.

Fig. 4. Partial proteolysis of the AR-AF1 domain using EndoGluC. A Predicted cleavage sites for the proteases trypsin, chymotrypsin, and Endo-GluC. B Histidine-tagged wild-type or mutant AR-AF1 polypeptides were digested with Endo-GluC for 5, 10, 20, and $60 \mathrm{~min}$, and fragments were resolved by SDS-PAGE. Gels were stained with Coomassie blue. C Main bands (arrows in B) were analysed with ImageJ.

(For figure see next page.) 


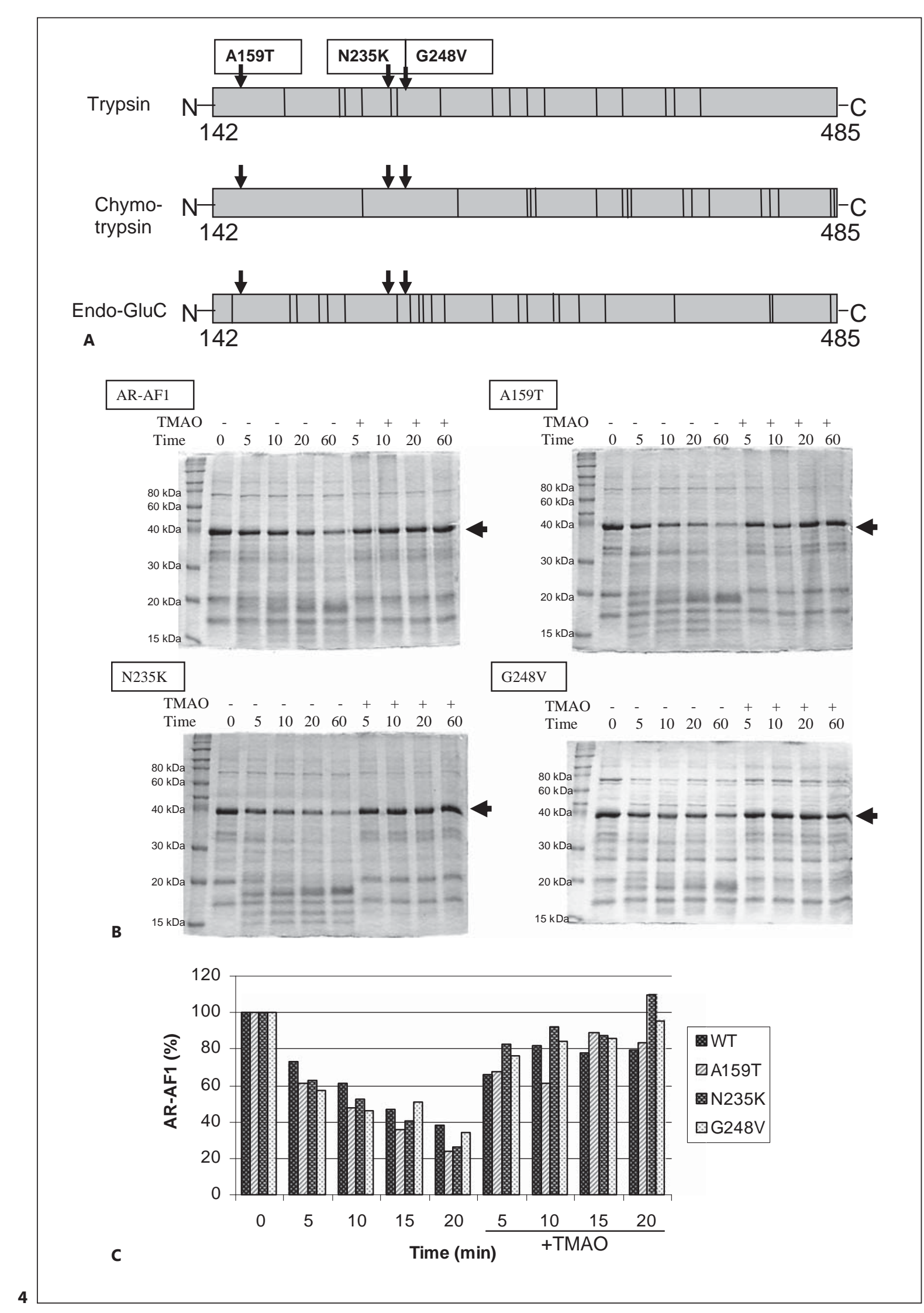




\section{Discussion}

It was well established that the $\mathrm{N}$ - and C-terminal domains of the AR play cooperative and independent roles in androgen signalling [Jääskeläinen et al., 2006], yet the precise molecular function of the AR-NTD remains poorly understood. In general, non-selective hormone responsive elements are more dependent on N-C interactions as compared to selective elements. Therefore, alterations within the AR-NTD are likely to have a more significant effect on non-selective response elements. Within the AR-NTD, amino acid sequence alignment analysis between species has revealed 3 highly conserved regions: residues 1-30, 224-258, and 500-541 [He et al., 2004; McEwan, 2004]. The first 30 amino acids include the ${ }^{23} \mathrm{FQNLF}^{27}$ motif, important for $\mathrm{N}-\mathrm{C}$ interaction [Jääskeläinen et al., 2006]. The region also interacts with MAGE-11, a bridging protein that stabilises co-activator interaction with AF2 [Bai et al., 2005]. Experimental studies indicated that RAP74 interacts with amino acids 224258. AR activity and interaction with RAP74 decreased by $60 \%$ as a consequence of a mutation of 3 residues within this domain [Betney and McEwan, 2003]. The spontaneous somatic AR mutations A236T and E238G (human numbering) identified in the TRAMP mouse prostate cancer model showed elevated levels of ligand-independent basal activity. E238G exhibited increased responsiveness to co-activators ARA160 and ARA70 and decreased interaction with the $\mathrm{COOH}$-terminus of the Hsp70-interacting protein, a negative regulator of the AR [Han et al., 2001; He et al., 2004].

The detailed structure-activity insights obtained from pathogenic $A R$ mutations identified in the AR-LBD and AR-DBD are currently limited for the AR-NTD. For this reason, we investigated 7 missense mutations and 2 insertion/deletions located in the AR-NTD in patients with AIS. The phenotypes associated with A159T, N235K, G248V, P380R, del57L, and ins58L are mild to partial forms of AIS. Mutations Q120E and L272F were associated with a more severe phenotype, and the patients were raised female. Interestingly, G216R was associated with a range of phenotypic variations manifested within the same family [Deeb et al., 2005].

Different response elements have previously been shown to influence AR activity [Reid et al., 2001]. The androgen-response elements in the Pem promoter are selective, and the levels of induction from the Pem promoter are lower than that observed for the promiscuous MMTV or GRE reporters. Furthermore, optimal nuclear receptor function is dependent upon accurate inter-do- main communication [Helsen et al., 2012] which can be influenced by allosteric mechanisms [Watson et al., 2013]. Therefore, these amino acid substitutions have identified structural domains within the AR, which play important roles in the recognition and response to distinct androgen-response elements. For this reason, the transactivation activity of identified AR-NTD mutations was tested using 2 AR-regulated luciferase reporters. Reduced Pemluciferase reporter activity was observed for A159T, N235K, G248Vl, and P380R as compared to wild-type AR; the loss of function was greater than that detected using the GRE-luciferase promoter. These results suggest a greater sensitivity of the Pem promoter to detect AR mutant dysfunction as previously reported [Zuccarello et al., 2008]. Furthermore, based on the Pem-luciferase reporter activity, it is likely that A159T, N235K, G248V, and P380R are pathogenic. Ala159 is located close to the PSTLSL motif which interacts with RAP74, the large component of TFIIF [Reid et al., 2002b]. Asn235 and Gly248 are located in a region highly conserved across species. Asn 235 is unique to humans, being a serine residue in other mammalian species. A change to lysine $(\mathrm{N} 235 \mathrm{~K})$ introduces a structurally distinct charged polar side chain as compared to serine or asparagine. This dramatic change is probably an important feature contributing to the loss of AR function. P380R showed a $20 \%$ decrease in transactivation on both promoters. Pro380 is the penultimate C-terminal residue of the 8-proline-stretch in the Tau-5 region of the AR-NTD. This proline repeat is highly conserved and, similar to other such repeats, may be a unique feature of intrinsically disordered regions [Simon and Hancock, 2009].

We performed protein structure analyses on mutations A159T, N235K, and G248V. Although these mutations are associated with severe functional defects, no significant structural differences were detected between the wild-type and the mutant AR-AF1 using fluorescence and limited proteolysis methods. This suggests the ARNTD can structurally tolerate such amino acid substitutions within the generally disordered structural arrangement of the AR-NTD, indicating that the loss of function observed in transactivation assays is not simply due to a change in the structure or folding of AF1. The results are consistent with the known flexible nature of the AF1 structure.

Missense mutations, identified in patients with severe AIS, showed normal or modest deficits in AR transactivation as compared to wild-type AR under the conditions employed. Q120E displayed an 20\% decreased activity using the GRE-luciferase reporter promoter detectable 
with DHT (1 nM), although this did not reach statistical significance. Consistently, this mutation was inherited via the maternal grandfather, suggesting that Q120E has a minimal pathogenic effect in this patient. Wild-type activity was detected for G216R using both Pem and GRE reporters. This mutation was identified in 6 patients from 3 different families; in 1 consanguineous family, 3 of 4 affected members were raised as female. This phenotypic variation suggests an involvement of other factors that may affect the degree of undervirilisation in patients harbouring the G216R mutation. Examples include fetal testosterone concentrations, co-regulator function, and secondary 5a-reductase deficiency [Boehmer et al., 2001]. It is also possible that a second mutation contributes to the sex reversal in these families, as has been recently described [Idkowiak et al., 2010].

Functional analysis of the ins58L mutation revealed a reduced expression as compared to the wild type. Transcriptional activity for ins58L was $\sim 30 \%$ lower than the wild-type AR in the stable cell lines. This suggests that ins58L is pathogenic and the likely cause of AIS. Further studies are required to define the molecular mechanism leading to a reduced AR-ins58L synthesis. Possible causes include reduced rates of transcription and/or translation, mRNA instability, or elevated rates of mutant receptor degradation. A family with AIS was reported with mutations in the Kozak and protein-coding $(\mathrm{E} 2 \mathrm{~K})$ regions of the $A R$ locus which resulted in reduced AR protein levels in transient expression studies [Choong et al., 1996a]. Expansion of the AR polyglutamine repeat associated with decreased AR activity has also been linked to reduced AR expression [Choong et al., 1996b]. However, the relationship between AR expression and disease phenotype remains poorly understood. For example, the hypomorphic mouse has an MAIS phenotype with normal male genital development, even though levels of AR expression are markedly reduced. It is possible that elevated testosterone levels rescue AR function [Arango et al., 1999]. The observation may reflect differences in the developmental role of androgens in mice and humans. In contrast, the expression levels and transactivation activity of del57L were similar to wild-type AR in HEK293 cells in this study. This mutation (described as L57Q) was recently reported to show loss of function in transfection studies using COS-7 cell lines [Hay and McEwan, 2012]. The discrepant results using different cellular assays may be explained by its environment, including factors such as intrinsic AR co-regulator levels.

The del57L and ins58L mutations have also been reported previously. ins58L was identified in 2 subjects with MAIS, identified in a cohort of infertile males [Lund et al.,
2003]. It was also found in human prostate cancer specimens and is a common variant in tumours developed in the humanised exon-1 mouse model of prostate cancer [O'Mahony et al., 2008]. del57L has been reported as a somatic mutation in a number of different cancer types, including prostate cancer [Tilley et al., 1996; Yeh et al., 2007]. However, the frequency of such in-frame insertions and deletions needs to be established in larger unaffected populations.

In conclusion, this study has illustrated that the detection of mild molecular defects due to AR-NTD mutations can be assay-dependent. Assay sensitivity may depend on the cell line, ligand, and promoter construct used [Simon and Mueller, 2006; Werner et al., 2006]. For this reason, we suggest that 2 or more promoters are used to test the function of the mutations (Pem/TAT-GRE, probasin/ MMTV), and the use of a second cell line should be considered (COS-1/PC-3, COS-1/HeLa). Probasin and PSA promoters may be a choice if the mutation involves $\mathrm{N}-\mathrm{C}$ interaction [He et al., 2002]. Cell lines also differ in their AR co-regulator complement and ability to metabolise natural androgens during the assay incubation period [Bebermeier et al., 2006]. Commonly used cell lines such as COS-1, HeLa, and PC-3 are poor activators of complex promoters such as the PSA promoter, suggesting the coregulator environment is not optimal for androgen-dependent gene activation. Therefore, new assays for measuring mutant AR function are required. Future developments may involve utilisation of recombinase-mediated cassette exchange (RMCE) or clustered regularly interspaced short palindromic repeats (CRISPR) technology to express mutant receptors and reporters in androgenresponsive lines relevant to sex development. This may allow the use of reporter gene assays in isogenic cell lines that contain the appropriate co-regulator complexes with androgen-regulated reporters in the appropriate chromatin and epigenetic contexts. Such assays may thus more closely reflect the endogenous gene environment and provide more detailed insights in the subtle functional roles of identified AR-NTD mutations.

\section{Acknowledgement}

We thank Dr. A. Brinkmann, Dr. Allera, and Dr. F. Claessens for the generous gifts of pSVAR0, pGRE2-TATA-Luc, and pPemLuc. We also thank V. Pilfold-Wilkie and K. Mooslehner for their excellent technical assistance. This study was funded by a GlaxoSmithKline International Scholarship and was supported by the NIHR Cambridge Biomedical Research Centre. We acknowledge the support of the University of Nottingham (N.P.M.). 


\section{References}

Arango NA, Lovell-Badge R, Behringer RR: Targeted mutagenesis of the endogenous mouse mis gene promoter: in vivo definition of genetic pathways of vertebrate sexual development. Cell 99:409-419 (1999).

- Audi L, Fernandez-Cancio M, Carrascosa A, Andaluz P, Toran N, et al: Novel (60\%) and recurrent (40\%) androgen receptor gene mutations in a series of 59 patients with a $46, \mathrm{XY}$ disorder of sex development. J Clin Endocrinol Metab 95:1876-1888 (2010).

- Bai S, He B, Wilson EM: Melanoma antigen gene protein MAGE-11 regulates androgen receptor function by modulating the interdomain interaction. Mol Cell Biol 25:1238-1257 (2005).

Barbulescu K, Geserick C, Schuttke I, Schleuning WD, Haendler B: New androgen response elements in the murine pem promoter mediate selective transactivation. Mol Endocrinol 15: 1803-1816 (2001)

- Bebermeier JH, Brooks JD, DePrimo SE, Werner $\mathrm{R}$, Deppe U, et al: Cell-line and tissue-specific signatures of androgen receptor-coregulator transcription. J Mol Med 84:919-931 (2006).

Betney R, McEwan IJ: Role of conserved hydrophobic amino acids in androgen receptor AF-1 function. J Mol Endocrinol 31:427-439 (2003).

Boehmer AL, Brinkmann AO, Nijman RM, Verleun-Mooijman MC, de Ruiter P, et al: Phenotypic variation in a family with partial androgen insensitivity syndrome explained by differences in $5 a$ dihydrotestosterone availability. J Clin Endocrinol Metab 86:12401246 (2001).

-Brinkmann AO, Faber PW, van Rooij HC, Kuiper GG, Ris C, et al: The human androgen receptor: domain structure, genomic organization and regulation of expression. J Steroid Biochem 34:307-310 (1989).

-Choong CS, Quigley CA, French FS, Wilson EM: A novel missense mutation in the amino-terminal domain of the human androgen receptor gene in a family with partial androgen insensitivity syndrome causes reduced efficiency of protein translation. J Clin Invest 98: 1423-1431 (1996a).

Choong CS, Kemppainen JA, Zhou ZX, Wilson EM: Reduced androgen receptor gene expression with first exon CAG repeat expansion. Mol Endocrinol 10:1527-1535 (1996b).

-Deeb A, Mason C, Lee YS, Hughes IA: Correlation between genotype, phenotype and sex of rearing in 111 patients with partial androgen insensitivity syndrome. Clin Endocrinol (Oxf) 63:56-62 (2005).

Ferlin A, Vinanzi C, Garolla A, Selice R, Zuccarello D, et al: Male infertility and androgen receptor gene mutations: clinical features and identification of seven novel mutations. Clin Endocrinol (Oxf) 65:606-610 (2006).
Giwercman YL, Nikoshkov A, Bystrom B, Pousette A, Arver S, Wedell A: A novel mutation $(\mathrm{N} 233 \mathrm{~K})$ in the transactivating domain and the N756S mutation in the ligand binding domain of the androgen receptor gene are associated with male infertility. Clin Endocrinol (Oxf) 54:827-834 (2001).

- Gottlieb B, Vasiliou DM, Lumbroso R, Beitel LK, Pinsky L, Trifiro MA: Analysis of exon $1 \mathrm{mu}-$ tations in the androgen receptor gene. Hum Mutat 14:527-539 (1999).

Gottlieb B, Beitel LK, Nadarajah A, Paliouras M, Trifiro $\mathrm{M}$ : The androgen receptor gene mutations database: 2012 update. Hum Mutat 33: 887-894 (2012).

- Han G, Foster BA, Mistry S, Buchanan G, Harris $J M$, et al: Hormone status selects for spontaneous somatic androgen receptor variants that demonstrate specific ligand and cofactor dependent activities in autochthonous prostate cancer. J Biol Chem 276:11204-11213 (2001).

Hay CW, McEwan IJ: The impact of point mutations in the human androgen receptor: classification of mutations on the basis of transcriptional activity. PLoS One 7:e32514 (2012).

He B, Lee LW, Minges JT, Wilson EM: Dependence of selective gene activation on the androgen receptor $\mathrm{NH} 2$ - and $\mathrm{COOH}$-terminal interaction. J Biol Chem 277:25631-25639 (2002).

${ }_{\mathrm{He}}$ B, Bai S, Hnat AT, Kalman RI, Minges JT, et al: An androgen receptor NH2-terminal conserved motif interacts with the $\mathrm{COOH}$ terminus of the HSP70-interacting protein (CHIP). J Biol Chem 279:30643-30653 (2004).

- Heemers HV, Tindall DJ: Androgen receptor (AR) coregulators: a diversity of functions converging on and regulating the AR transcriptional complex. Endocr Rev 28:778-808 (2007).

Helsen C, Dubois V, Verfaillie A, Young J, Trekels $\mathrm{M}$, et al: Evidence for DNA-binding domainligand-binding domain communications in the androgen receptor. Mol Cell Biol 32: 3033-3043 (2012)

-Hughes IA, Davies JD, Bunch TI, Pasterski V, Mastroyannopoulou K, MacDougall J: Androgen insensitivity syndrome. Lancet 380:14191428 (2012).

Idkowiak J, Malunowicz EM, Dhir V, Reisch N, Szarras-Czapnik M, et al: Concomitant mutations in the p450 oxidoreductase and androgen receptor genes presenting with $46, \mathrm{XY}$ disordered sex development and androgenization at adrenarche. J Clin Endocr Metab 95: 3418-3427 (2010).

Jääskeläinen J: Molecular biology of androgen insensitivity. Mol Cell Endocrinol 352:4-12 (2012). \ääskeläinen J, Deeb A, Schwabe JW, Mongan NP, Martin H, Hughes IA: Human androgen receptor gene ligand-binding-domain mutations leading to disrupted interaction between the N- and C-terminal domains. J Mol Endocrinol 36:361-368 (2006).

-Jenster G, van der Korput HA, Trapman J, Brinkmann AO: Identification of two transcription activation units in the $\mathrm{N}$-terminal domain of the human androgen receptor. J Biol Chem 270:7341-7346 (1995).

Kazemi-Esfarjani P, Trifiro MA, Pinsky L: Evidence for a repressive function of the long polyglutamine tract in the human androgen receptor: possible pathogenetic relevance for the (CAG)n-expanded neuronopathies. Hum Mol Genet 4:523-527 (1995).

Knoke I, Allera A, Wieacker P: Significance of the CAG repeat length in the androgen receptor gene $(A R)$ for the transactivation function of an M780I mutant AR. Hum Genet 104:257261 (1999).

Kumar R, Betney R, Li J, Thompson EB, McEwan IJ: Induced alpha-helix structure in AF1 of the androgen receptor upon binding transcription factor TFIIF. Biochemistry 43:30083013 (2004).

Lavery DN, McEwan IJ: Structural characterization of the native $\mathrm{NH}_{2}$-terminal transactivation domain of the human androgen receptor: a collapsed disordered conformation underlies structural plasticity and protein-induced folding. Biochemistry 47:3360-3369 (2008).

- Lund A, Juvonen V, Lahdetie J, Aittomaki K, Tapanainen JS, Savontaus ML: A novel sequence variation in the transactivation regulating domain of the androgen receptor in two infertile Finnish men. Fertil Steril 79 Suppl 3: 1647-1648 (2003).

McEwan IJ: Molecular mechanisms of androgen receptor-mediated gene regulation: structure-function analysis of the AF-1 domain. Endocr Relat Cancer 11:281-293 (2004).

Mueller OT, Mason-Suares H, Root A: Gene symbol: AR. Disease: androgen insensitivity syndrome. Hum Genet 119:681 (2006).

O'Mahony OA, Steinkamp MP, Albertelli MA, Brogley M, Rehman H, Robins DM: Profiling human androgen receptor mutations reveals treatment effects in a mouse model of prostate cancer. Mol Cancer Res 6:1691-1701 (2008).

Reid KJ, Hendy SC, Saito J, Sorensen P, Nelson CC: Two classes of androgen receptor elements mediate cooperativity through allosteric interactions. J Biol Chem 276:2943-2952 (2001).

Reid J, Kelly SM, Watt K, Price NC, McEwan IJ: Conformational analysis of the androgen receptor amino-terminal domain involved in transactivation. Influence of structure-stabilizing solutes and protein-protein interactions. J Biol Chem 277:20079-20086 (2002a). 
Reid J, Murray I, Watt K, Betney R, McEwan IJ: The androgen receptor interacts with multiple regions of the large subunit of general transcription factor TFIIF. J Biol Chem 277: 41247-41253 (2002b).

Simon M, Hancock JM: Tandem and cryptic amino acid repeats accumulate in disordered regions of proteins. Genome Biol 10:R59 (2009).

Simon S, Mueller SO: Human reporter gene assays: transcriptional activity of the androgen receptor is modulated by the cellular environment and promoter context. Toxicology 220: 90-103 (2006).

Tilley WD, Buchanan G, Hickey TE, Bentel JM: Mutations in the androgen receptor gene are associated with progression of human prostate cancer to androgen independence. Clin Cancer Res 2:277-285 (1996).
Wang Q, Ghadessy FJ, Yong EL: Analysis of the transactivation domain of the androgen receptor in patients with male infertility. Clin Genet 54:185-192 (1998).

Watson LC, Kuchenbecker KM, Schiller BJ, Gross JD, Pufall MA, Yamamoto KR: The glucocorticoid receptor dimer interface allosterically transmits sequence-specific DNA signals. Nat Struct Mol Biol 20:876-883 (2013).

Werner R, Schutt J, Hannema S, Ropke A, Wieacker P, et al: Androgen receptor gene mutations in androgen insensitivity syndrome cause distinct patterns of reduced activation of androgen-responsive promoter constructs. J Steroid Biochem Mol Biol 101: 1-10 (2006).

Yeap BB, Wilce JA, Leedman PJ: The androgen receptor mRNA. Bioessays 26:672-682 (2004).
Yeh SH, Chiu CM, Chen CL, Lu SF, Hsu HC, et al: Somatic mutations at the trinucleotide repeats of androgen receptor gene in male hepatocellular carcinoma. Int $\mathrm{J}$ Cancer 120 : 1610-1617 (2007).

Zhou XE, Suino-Powell K, Ludidi PL, McDonnell DP, Xu HE: Expression, purification and primary crystallographic study of human androgen receptor in complex with DNA and coactivator motifs. Protein Expr Purif 71:21-27 (2010).

Zuccarello D, Ferlin A, Vinanzi C, Prana E, Garolla A, et al: Detailed functional studies on androgen receptor mild mutations demonstrate their association with male infertility Clin Endocrinol (Oxf) 68:580-588 (2008). 